eISSN: 2172-9077

https://doi.org/10.14201/fjc201918119140

\title{
LA OBJETIVIDAD Y NEUTRALIDAD DE LA INFORMACIÓN EN LA RED: EL TRATAMIENTO DEL Diario.ES, ABC.ES Y El PAÍ́S.COM EN EL JUICIO CONTRA «LA MANADA»
}

\section{The objectivity and neutrality of information on the network: the informative treatment of Eldiario.es, ABC.es, and ElPais. com in the judgment against "La Manada"}

\author{
Egr. Cintia LIARTE MARÍN \\ Universidad de Zaragoza. España \\ E-mail: cintialiarte37@gmail.com \\ (iD https://orcid.org/0000-0002-0434-4359 \\ Dra. Elena BANDRÉS GOLDÁRAZ \\ Profesora Asociada \\ Universidad de Zaragoza. España \\ E-mail: bandres@unizar.es \\ iD http://orcid.org/0000-0003-0898-2232
}

Fecha de recepción del artículo: 07/09/2018

Fecha de aceptación definitiva: 28/01/2019

\begin{abstract}
RESUMEN
La sociedad española sufrió una verdadera convulsión tras el proceso judicial llevado a cabo a los componentes de "La Manada", el apelativo con el que se conoció a los cinco jóvenes considerados por la Audiencia de Navarra culpables de abusar sexualmente de una joven de 18, en los Sanfermines de 2016. Tanto el juicio, como el fallo de la sentencia, generó toda una corriente social de oposición al sistema judicial al considerar que el tribunal creyó más a los agresores que a la víctima, según la opinión pública vertida en redes sociales. En este artículo se investiga el tratamiento mediático que, sobre esta sentencia, se lleva a cabo en tres medios de comunicación on line para determinar el grado de independencia periodística, objetividad y de neutralidad respecto al tema tratado en la red, tras esta sentencia que ha supuesto un antes y un después en la concepción de la violencia sexual contra las mujeres.
\end{abstract}

Palabras clave: ciberobjetividad; ciberneutralidad; "La Manada»; violencia sexual; cibermedios; feminismo.

\begin{abstract}
Spanish society has suffered a real unrest after the judicial process on the members of «La Manada", the nickname used for the five young men deemed guilty of sexual assault on an 18-year-old woman by the Navarra Court, in the San Fermin Festivals in 2016. Not only
\end{abstract}




\begin{abstract}
the trial but also the judgement has created a social movement against the judicial system on account of the court believing the sex offenders rather than the victim, according to the opinion expressed in social networks. This article focuses on the media treatment, independence, objectivity and neutrality, made by three mass media mentioned on the title as well as the coverage and reaction to the process which prove that the judgement and its consequences have meant a before and an after in the idea of sexual violence against women.
\end{abstract}

Key words: «La Manada»; sexual violence; sexual abuse; cybermedia; feminism.

\title{
1. INTRODUCCIÓN
}

La Sección Segunda de la Audiencia Provincial de Navarra hizo pública, el 26 de abril de 2018, la sentencia en la que se condenó a nueve años de prisión a cada uno de los cinco acusados de haber violado en grupo a una joven de 18 años, dos años antes, durante las fiestas de San Fermín en Pamplona, Navarra. Una sentencia que se produjo cinco meses después de haberse celebrado el juicio. El Tribunal redujo el delito de agresión sexual a delito de abuso sexual continuado, al no considerar probado que hubiera existido violencia o intimidación para la ejecución del delito, conforme lo exige el Código Penal. Tanto el Ministerio Fiscal como la acusación particular, junto con las dos acusaciones populares ejercidas por el Gobierno de Navarra y por el Ayuntamiento de Pamplona, calificaron el delito de agresión sexual. Además, la sentencia condenó a uno de los cinco agresores a pagar a la víctima 900 euros por la sustracción de su teléfono móvil al ser calificado como hurto leve y exculpó a los cinco de otro delito contra la intimidad de la joven por haber grabado en vídeo los hechos.

Este proceso judicial fue apodado en los medios de comunicación como «Juicio de La Manada", por ser el nombre del grupo de Whatsapp que los cinco acusados mantenían con más integrantes y a través del cual contaron los hechos al resto que no estuvo en Pamplona, aquel 7 de julio de 2016.

Esta sentencia contó con el voto particular de uno de los tres magistrados a través del cual pidió la libre absolución de los acusados por considerar que la víctima no opuso resistencia ni dio muestras en ningún momento de rechazar el contacto sexual, tal y como se refleja en la página 57 de su voto particular. Para la opinión mayoritaria del tribunal (dos de los tres jueces que compusieron la terna) quedó probado el delito de abusos sexuales, tal y como refleja la sentencia en la pág. 28 pero descartaron el uso de la violencia. Sí destacaron la existencia de "prevalimiento» (pág. 46), es decir, la superioridad con respecto a la víctima para poder cometer delito.

La sentencia generó, en apenas 24 horas, una ola de indignación ciudadana sin precedentes que se fraguó en un millón de firmas recogidas en la plataforma Change.org y cientos de manifestaciones por todo el país bajo el grito de "yo sí te creo, hermana».

\section{OBJETIVOS E HIPÓTESIS}

Son varios los objetivos que se intentan conseguir en este análisis sobre las repercusiones sociales de la polémica sentencia del caso «La Manada». En primer lugar, se quiere analizar el tratamiento informativo mostrado en los medios de comunicación con el fin de analizar el grado de objetividad y de neutralidad desplegado, en un 
contexto de presión social y mediática exacerbada y sin precedentes en España. Para ello se ha llevado a cabo un estudio en tres medios digitales: ABC.es, Elpaís.com y El diario.es.

También se pretende conocer si este tratamiento informativo ha sido homogéneo en los tres medios o, por el contrario, ha habido diferencias sustanciales sobre la manera en la que se ha comunicado la sentencia. Otro de los enfoques consiste en averiguar si los medios analizados contienen ideología de género en las crónicas y artículos de opinión escritos. El cuarto objetivo radica en averiguar si el tratamiento informativo ha motivado la movilización de las personas que salieron a la calle para manifestar su rechazo a la sentencia y, también, solicitar la «eliminación de la justicia patriarcal» $y$, por consiguiente, si ha servido para aglutinar e impulsar un movimiento social que haya sentado las bases de un nuevo movimiento feminista.

Como hipótesis, planteamos que existe poco hueco para la subjetividad ya que informar sobre una sentencia judicial es una tarea en la que queda muy poco margen para ello al tener que hacerse eco este tipo de periodismo especializado de un acto dictado por un tribunal, en una sentencia escrita.

\section{Metodología}

Para llevar a cabo esta investigación se han analizado tres medios de comunicación on line por ser los más representativos en cuanto a polaridad ideológica (ABC y El País), mientras que se ha elegido Eldiario.es, por convertirse en uno de los nuevos digitales que más seguidores tiene. Concretamente, Eldiario.es es el segundo medio nativo digital más leído, después de El Confidencial pero éste se ha descartado, sin embargo, por estar especializado en noticias financieras, económicas y políticas. Otra de las razones por las que se han seleccionado medios digitales frente a los convencionales en papel, u otros medios es por la continua actualización de las noticias para cubrir la última hora, la rapidez en la información y la posibilidad de interacción de los usuarios con las publicaciones a través de los comentarios.

El análisis se ha centrado en la cobertura informativa realizada por los tres medios mencionados de la sentencia contra "La Manada", durante el mismo día en el que esta fue hecha pública. Se ha llevado a cabo un método de análisis contenido, indicado según Bardin (1996, p. 33) para "tratar de saber lo que hay detrás de las palabras a las que se dedica. La lingüística es un estudio de la lengua, el análisis de contenido es una encuesta, a través de mensajes, de otras realidades», a la vez que se ha seguido el análisis crítico del discurso (ACD) de Teun A. Van Dijk al considerar el discurso de los medios y, por lo tanto, también la noticia, como una forma particular de práctica social. Y, en este caso, este tipo de análisis es especialmente idóneo porque permite analizar las noticias desde un componente textual y otro contextual. A través del componente textual analizaremos, siguiendo al autor (1990, p. 49) «sistemáticamente las diferentes estructuras del discurso periodístico en diferentes niveles» y, a través del componente contextual analizaremos (Van Dijk, 1990, p. 250) «los factores cognitivos y sociales, las condiciones, los límites o las consecuencias de estas estructuras textuales". A través de este análisis averiguaremos qué tipo de ideología, en el caso de que exista, se reproduce o se construye en la información periodística sobre este caso. 


\section{MARCo TEÓRICO}

El 26 de abril de 2018, miles de mujeres tomaron las calles en diferentes ciudades españolas, para expresar su indignación tras conocer ese día la sentencia dictada por la Audiencia de Navarra en la que se exculpó de violación a los integrantes del grupo de "La Manada». Fueron manifestaciones multitudinarias, protagonizadas mayoritariamente por mujeres, para visibilizar el apoyo a otra mujer, la joven de 18 años a la que el tribunal navarro no creyó que fuera violada al no existir, según el fallo, "ni violencia ni intimidación». Las manifestaciones se convocaron a través de las redes sociales de manera casi espontánea ante la convocatoria de cientos de movimientos y asociaciones feministas en todo el Estado Español. La ola de protestas volvió a sacudir las calles españolas un mes después de que 5,3 millones de mujeres protagonizaran una huelga sin precedentes el 8 de marzo, día Internacional de la Mujer.

Este tipo de protestas, no por ser inusual, también ha tenido en los albores del siglo XX, al menos varios precedentes, como el sucedido el 15 de septiembre de 1907, en París, cuando tuvo lugar una manifestación de mujeres y niños para protestar por la puesta en libertad del asesino de una niña parisina. Tal y como recoge el periódico La Vanguardia, al día siguiente,

Respondiendo a la convocatoria de una carta firmada por varias madres de familia y que han publicado Le Matin y otros periódicos, unas mil mujeres y niños han intentado formar una manifestación en la plaza de Santa Ambrosia, cerca de la casa de la pequeña Marta, la infeliz víctima de Soleillant. Su intento era hacer una ruidosa manifestación contra el indulto del asesino y luego ir hasta la plaza Vendome para protestar ante el ministerio de Justicia. La policía ha logrado dispersarles sin violencia. Hasta las cinco de la tarde no se ha producido ningún incidente. Algunos grupos de manifestantes han intentado reunirse y pasando por los bulevares llegar hasta la plaza de Vendôme, profiriendo diversos gritos que pueden condensarse en los del justicia! y iAbajo Soleillant! La policía les ha dispersado fácilmente pudiendo considerarse abortada la manifestación.

Otro suceso acontecido en 1910 en Barcelona, que recuerda también, en la distancia, al asunto que nos ocupa, sirvió para poner a prueba esta conciencia de solidaridad e indignación por la violación de una niña de siete años en un convento en el que vivía de manera temporal. La Madre Superiora pidió a la madre de la niña que se la llevara del convento por sufrir una enfermedad venérea contagiosa, cuando en realidad, la niña fue violada. Según recoge Temma Kaplan (1990, pp. 275-276),

La comunidad femenina de Barcelona adoptó a la niña como propia. (...) un gran número de mujeres humildes, descritas como «mujeres del pueblo», y de vendedoras de los mercados del Borne y la Barceloneta, de la parte antigua de la ciudad, se congregó frente a la casa de la niña. No pasaron por la iglesia; pocas mujeres se incorporaron a las manifestaciones anticlericales que habían organizado los hombres. Lo que parecía estar en disputa para las mujeres era la solidaridad con la madre y su hija enferma, antes que el rencor contra la iglesia. (...) La policía trató de persuadir a la madre de que su hija había participado en actos inmorales fuera de la escuela del convento, pero las mujeres se sintieron tan ultrajadas como la madre, que proclamaba la inocencia de su hija. (...) No abandonaron su barriada para atacar el convento, como hicieron los hombres. Consolidaron sus lazos como mujeres, madres y vecinas, a través de la charla, las ayuda y pequeñas contribuciones financieras (...) Sólo cuando el caso fue a los tribunales para 
una interrogación oficial, salieron las mujeres con este motivo de la barriada y actuaron políticamente. Promovieron manifestaciones en la Plaza del Obispo Urquinaona (...) Cuando las mujeres pretendieron unirse como tales, alarmaron a las autoridades y el gobernador prohibió la concentración».

Otro tipo de motivaciones, como la carestía de los productos de primera necesidad desde el siglo XVIII hasta principios del siglo XX, marcaron también los inicios de las manifestaciones de mujeres. Lo que se conoce como "revueltas primitivas" (Asín, en Baras y Montero, 1987) durante el Antiguo Régimen, representan las protestas multitudinarias por el alza de los precios de productos básicos en Francia, Inglaterra o España. El motín de Esquilache fue uno de ellos y tuvo lugar en diferentes ciudades españolas para protestar contra el alza del precio del pan. Zaragoza fue la segunda ciudad en la que más virulencia cobraron las protestas. Conocido como «motín de los broqueleros» por llevar los insurrectos broqueles (pequeños escudos de madera para defenderse), palos y cuchillos, este día quedó reflejado en el libro «Los hechos acontecidos el 6 de abril de 1766 en Zaragoza", en el que Thomas Sebastian y Latre, por encargo del Marqués de Castelar, gobernador y Capitán General del Reino de Aragón, dejó constancia del levantamiento popular contra el Intendente Marqués de Avilés por no rebajar el precio del pan y contra los usureros y acaparadores de trigo. Las mujeres tomaron parte activa en estas protestas, tal y como recoge el autor en el castellano de la época (Baras y Montero, 1987, p. 29).

Los primeros que llegaron de todo el motín a casa del Intendente fueron las mujeres, y muchachos, (porque estos pequeños, y débiles resortes suelen ser los que empiezan a dar movimiento a estas grandes máquinas) empezaron a apedrear los balcones, y luego apoderándose de la Guardia los amotinados, subieron arriba.

En los primeros meses de la Revolución Francesa, las mujeres también protagonizaron una gesta el cinco y seis de octubre de 1789, cuando seis mil parisinas fueron andando desde la ciudad del Sena hasta el palacio de Versalles, donde se alojaban los reyes de Francia, para reclamar alimentos y pedir que bajara el precio del pan ya que los salarios no llegaban para cubrir las necesidades básicas de las familias. Las mujeres siguieron luchando en la Revolución Francesa también para lograr ser ciudadanas en igualdad de derechos con los ciudadanos. Se organizaron entre ellas, se unieron, expresaron sus reclamaciones en los Cuadernos de Quejas y como apunta Ana de Miguel, (1995) siguiendo a Fraisse, las mujeres pasaron «del gesto individual al movimiento colectivo: la querella es llevada a la plaza pública y toma la forma de un debate democrático: se convierte por vez primera de forma explícita en una cuestión política», aunque luego el feminismo fuera, como sigue diciendo De Miguel, amargamente derrotado en la Revolución Francesa, ya que el único derecho que el gobierno revolucionario otorgará a las mujeres, como recoge Alicia Puleo (1993, p. 155) «será el reconocido artículo X de su Declaración, el de subir al cadalso como los hombres». Las mujeres siguieron viviendo en el Antiguo Régimen a pesar de su abolición por la Revolución Francesa, debido al Código Civil napoleónico que confirió a las mujeres un estado legal de minoría de edad permanente hasta bien entrado el siglo XX.

En Estados Unidos se inicia en 1848, la lucha sistematizada por conseguir el derecho al voto para las mujeres. Cerca de setenta mujeres y una treintena de hombres firmaron el manifiesto "Declaración de sentimientos", conocido como declaración de Seneca Falls, por ser la localidad en la que se firmó, en el que Alicia Miyares (1999) 
afirma encontrar "dos grandes apartados teóricos: de un lado, las exigencias para alcanzar la ciudadanía civil y, de otro lado, los principios que deberían modificar las costumbres y la moral».

En España, las luchas sufragistas tardarán más de cinco décadas en llegar. Pero serán de nuevo los motines del pan y las luchas para mejorar las condiciones en el trabajo, especialmente las de las madres, lo que canalice las principales protestas de las mujeres a principios de ese siglo, así como las manifestaciones contra las diferentes guerras coloniales para reivindicar que sus hijos o maridos no fueran reclutados. Causas que fueron defendidas por Carmen de Burgos, conocida como Colombine, la primera corresponsal de guerra española (Paino, Jiménez y Rodríguez, 2016). Como recoge Helena Establier, citando a Sanfeliú (2005),

Desde julio de 1896 muchas mujeres se manifestaban en contra en Zaragoza y otras ciudades españolas. Una de las primeras protestas contra la guerra fue encabezada por un grupo de mujeres de Zaragoza, que, a mediados de julio de 1896, solicitó permiso al gobernador interino para una manifestación contra un nuevo envío de tropas a Cuba. El gobernador denegó el permiso y anunció represalias, pese a lo cual el 1 de agosto un grupo de jóvenes y mujeres recorrieron la ciudad con una pancarta en la que se pedía el cese de envío de soldados a América. A imagen y semejanza de ésta, se llevaron a cabo otras protestas similares en Barcelona o Valencia, ciudad en la que un grupo de defensoras de la paz permaneció durante varios meses detenidas en el Asilo-Cárcel.

Las crisis cíclicas provocadas por las malas cosechas y la sequía continúan en los inicios del Siglo XX en España, en donde las mujeres continuaron siendo las protagonistas de numerosas protestas en diferentes puntos de España. Las conocidas como "revueltas primitivas" pasan a llamarse "motines de subsistencia», para exigir la bajada de los precios del pan y de otros productos de primera necesidad. El 25 de febrero de 1915, cincuenta y dos mujeres, algunas con sus hijos e hijas, llegaron a Huesca desde la localidad oscense de Lanaja, en carros tirados por caballos, para pedir al Gobernador que solucionara esa situación de hambre y miseria. Como recoge Joaquín Pisa (2014, p. 100),

Iban a manifestarse al día siguiente pidiendo pan y trabajo, junto a mujeres de Almudévar, Berbegal, Robres, Torralba y otros lugares de la provincia de Huesca que debían llegar a la capital altoaragonesa en las horas siguientes»

Las mujeres de Lanaja no lograron su objetivo y fueron expulsadas de la ciudad por la Guardia Civil, de madrugada. Diferentes colectivos escribieron una carta al diputado por Caspe en las Cortes Generales para manifestar el desafuero, tal y como se recoge en el periódico La Vanguardia, el 28 de febrero de 1915. 


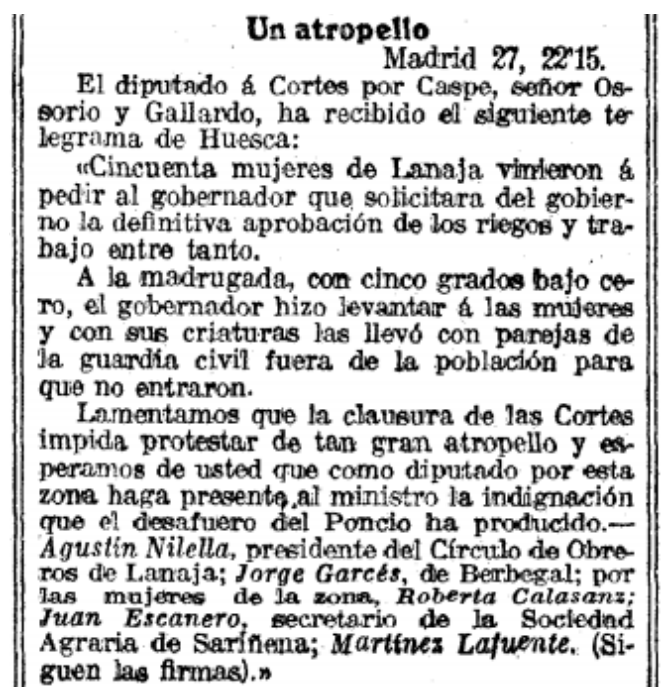

Tres años después, siguen los conflictos por esta causa y en «Barcelona, Alicante, Almería y Málaga» (María Dolores Ramos, 1993, p. 656) salen a la calle miles de mujeres, pero también para pedir mejoras en las condiciones laborales. Como sigue diciendo esta autora (1993, p. 657) en enero de 1918, se produjeron numerosas manifestaciones de mujeres motivadas por:

el alza incontrolada del precio de las subsistencias desde los inicios de la Primera Guerra Mundial (...) manifestaciones en las que se proferían gritos significativos: «iMujeres a la calle para defendernos contra el hambre!», «En nombre de la humanidad las mujeres toman las calles!» (Barcelona), «iCompañeros, nosotras somos las que tenemos que arreglar esto!», «Fuera hombres!» (Málaga); asalto de mercados, decomiso de víveres, visitas al gobernador y al alcalde, mitin femenino multitudinario.

Todos estos acontecimientos suponen el inicio de una conciencia femenina que según Temma Kaplan (1990, p. 268) «se centra en los derechos del género, en intereses sociales y en la supervivencia».

Las luchas de mujeres se centran, tras la proclamación de la II República en España, en la lucha por el sufragio femenino que llega a su culmen el 1 de octubre de 1931, con la aprobación en las Cortes Constituyentes por 161 votos a favor, frente a 121 en contra, del derecho al sufragio femenino como derecho fundamental recogido en la nueva Constitución. Un enconado debate llevado al Parlamento y a la sociedad por Clara Campoamor, diputada del partido Radical Republicano que recogía en su programa electoral personal conceder a las mujeres el derecho a votar. Tal y como recogen las crónicas periodísticas plasmadas por la propia Clara Campoamor,

La concesión del voto a las mujeres, acordada ayer por la Cámara, determinó un escándalo formidable que continuó luego en los pasillos (...) Es posible que la trascendental votación de anoche tenga consecuencias graves en otro orden nacional. (La Voz, de 2 de octubre). [2006, p. 140] 
El debate sobre el voto femenino estaba en todas partes y, especialmente, porque las dos únicas mujeres que lograron entrar en la Cámara compuesta por 470 diputados, Clara Campoamor y Victoria Kent, defendieron posiciones antagónicas. Quedará también para la historia el discurso de Campoamor cuando rebatió los argumentos contrarios a permitir el sufragio femenino. Argumentos de todo tipo, muchos de ellos peregrinos, que acusaban a las mujeres de no participar ni defender la República, y que votarían en contra de este sistema de gobierno influenciadas por sus maridos y por sus confesores. Dijo Campoamor:

Respecto a la serie de afirmaciones que se han hecho esta tarde contra el voto de la mujer, he de decir, con toda la consideración necesaria, que no están apoyadas en la realidad. Tomemos al azar algunas de ellas. ¿Qué cuándo las mujeres se han levantado para protestar de la guerra de Marruecos? Primero: ¿y por qué no los hombres? Segundo: ¿quién protestó y se levantó en Zaragoza cuando la guerra de Cuba más que las mujeres? ¿Quién nutrió la manifestación pro responsabilidades del Ateneo, con motivo del desastre de Annual, más que las mujeres, que iban en mayor número que los hombres? ¡Las mujeres! ¿Cómo puede decirse que cuando las mujeres den señales de vida por la República se les concederá como premio el derecho a votar? ¿Es que no han luchado las mujeres por la República? [2010, p. 124]

\section{El PERIODISMO JUdiCIAL EN LOS MEDIOS DIGITALES}

Calero y Ronda definen periodismo judicial (2000, p. 18) «como aquella especialidad informativa que se ocupa de transmitir a la opinión pública el desarrollo y contenido de las actuaciones más relevantes socialmente de los órganos de la administración de justicia. Incluso jurisprudencialmente se ha dado carta de naturaleza a este concepto». José Antonio Zarzalejos (1998, p. 20) considera crónica judicial «el relato, por un medio de comunicación de los acontecimientos desarrollados en el curso de un procedimiento judicial. Se trata, por tanto, de una actividad doble, consistente, en primer lugar, en la toma de conocimiento de la realidad jurisdiccional y, en segundo lugar, en el traslado de esa realidad al ciudadano por los diversos cauces informativos de la forma más clara y comprensible». Para Zarzalejos, el periodista judicial debe tener en cuenta en una crónica judicial: «respeto a la imparcialidad judicial, respeto a la imagen e intimidad de las víctimas, respeto a la imagen y presunción de inocencia del acusado" (Ibid.).

En el tratamiento de la información en los medios digitales resulta clave la capacidad de actualización e interacción que permite, respecto a los medios convencionales estar conectado e informado en todo momento al público. Como afirma Núñez Ladevéze (2015, p. 120),

esto permite producir la información por fases, de un modo interactivo. Es decir, en lugar de completar un ciclo noticioso al día, la jornada informativa digital consiste en una sucesión de breves ciclos, que no vienen marcados por la hora de cierre, sino por la necesidad de ampliar las informaciones e incluir otras nuevas. Esto se suele denominar cierre continuo y permite que una pieza pueda salir web first, es decir, en medios digitales antes que en los medios tradicionales. 
Dos de los medios analizados en este trabajo utilizaron la actualización en directo para informar de la lectura de la sentencia; en una sola página iban añadiendo las nuevas informaciones y reacciones que llegaban en tiempo real, en vez de crear diferentes noticias separadas, apostaron por integrar toda la información en una sola, de forma que el lector pudiera seguir de manera cronológica todo lo que estaba ocurriendo.

\section{LA SENTENCIA DEL JUICIO «LA MANADA»}

\section{- Tratamiento en los 3 medios digitales (ABC.es, Elpaís.com, Eldiario.es)}

Siguiendo la metodología ya referida del análisis crítico del discurso (ACD) de Van Dijk, analizaremos titulares, subtítulos, cuerpo de texto, utilización de las fotografías y también, palabras clave empleadas en el desarrollo de la noticia. Otro de los objetivos fundamentales de este análisis va a ser determinar si existe sexismo o machismo en el tratamiento de la información, si se culpabiliza a la víctima o si el medio se sitúa a favor o en contra del dictamen. Esta preocupación es una de las bases del Análisis Crítico del Discurso de Van Dijk, (en Wodak y Meyer, 2003, p. 150):

Si tenemos interés en un estudio crítico del papel del discurso en la reproducción del sexismo o el machismo en la sociedad, es característico que no nos limitemos a estudiar las bastante específicas estructuras de la entonación y el volumen, y lo más probable será que comencemos, por un lado, con un estudio del control de la interacción, y con un análisis del "contenido" -como la elección de temas, proposiciones y elementos léxicos-, por otro. La razón estriba en que estas formas de significado parecen estar más directamente relacionadas con las creencias, y de ahí las actitudes y las ideologías que los hombres sexistas verifican o expresan cuando hablan con (o acerca de) las mujeres.

No obstante, es importante aclarar que no afirmamos de antemano que los roles sexistas y machistas se reproduzcan en las diferentes noticias de estos tres medios digitales, sino que partimos de esa hipótesis con el objetivo de determinar si se encuentran esas estructuras en dichos discursos mediáticos. Además, analizaremos las noticias en función de las estructuras que generan las noticias, tanto en el título, en el subtítulo y en el texto, además de la presencia de fotografías. Extraeremos de las frases el sujeto que realiza la acción, el «tópico» y el «comento», el foco de la acción, teniendo en cuenta que puede haber más de uno en cada frase. También se analizarán los adjetivos que acompañan la descripción que conforma el comento. Como afirma Van Dijk (1980, p. 181) «un tópico es cierta función que determina acerca de qué cosas se está diciendo algo. De modo semejante, un tópico se asocia a menudo con lo que "ya se sabe» (por el oyente) en algún contexto de conversación, o lo que "es presupuesto» (para ser identificado) por alguna oración. El comento, entonces, se asocia con lo que "no se sabe» (por el oyente)».

\subsection{Tratamiento informativo de ABC.es}

En 2016, ABC.es se situó como el segundo periódico más leído en España, por detrás de Elpaís.com, según la OJD. Además, a finales de ese año consiguió alcanzar un récord de audiencia sobrepasando los 16,5 millones de navegadores únicos. 
También se ha tenido en cuenta la polaridad ideológica que presenta frente a Elpaís.com, uno de sus principales competidores. Por otra parte, es importante puntualizar que la selección de las noticias se hizo en tiempo real el mismo día en que se leyó la sentencia, el 26 de abril de 2018.

Tan solo media hora después de la lectura del fallo, se publicaron cuatro noticias que se fueron actualizando constantemente con la llegada de nuevos datos o testimonios.

- Sentencia de "La Manada»: Condenados los cinco acusados a 9 años de prisión por abuso sexual. (26/04/18, actualizada 16:09h.) Este fue el titular que encabezó una de las primeras noticias publicadas minutos después de la lectura del fallo. Está redactada por Pablo Ojer quien se ha encargado de cubrir tanto la lectura de la sentencia en abril como el desarrollo del proceso judicial, en noviembre de 2017. El titular es aséptico, objetivo y sin ninguna carga subjetiva; informa de los años de condena. En el subtítulo explica que «el tribunal les ha absuelto del delito de agresión sexual y contra la intimidad». De esta manera, el lector entiende nada más comenzar a leer la noticia cuál es la noticia que tanto revuelo causó después: los acusados han sido condenados por abuso sexual y no por agresión, es decir, no por violación. En el cuerpo del texto explica, de manera breve e individual, la condena de cada uno de los acusados. El sujeto de esta noticia es "La Manada" (los cinco acusados y ahora condenados), el tópico como ya hemos dicho es lo que se asocia a lo que el oyente o lector ya sabe y en este caso es la condena; es decir, el público sabía que el 26 de abril se leía la sentencia con la condena, pero no sabían exactamente cuáles eran los delitos por los que se les condenó. Entonces, el comento en esta noticia es el abuso sexual, ya que es la nueva información que el periodista aporta al lector y que este último no conocía. Además, en esta pieza, el redactor cuenta el contexto de malestar que se generó a las puertas de la Audiencia Provincial de Navarra. Dice la noticia:

Al grito de «es violación, no es abuso", (...) varios centenares de personas, muchas de ellas exhibiendo manos rojas, símbolo contra las agresiones sexistas, permanecen concentradas ante las puertas del Palacio de Justicia, donde han expresado de esta forma su disconformidad con el fallo y han repetido la consigna de "yo sí te creo».

La noticia viene precedida por un vídeo titulado: "La sentencia de La Manada», de elaboración propia en la que aparecen cada uno de los condenados, con su nombre y las iniciales de su apellido y debajo el año de nacimiento. En otra línea aparece la condena impuesta y, en otra, una información sobre su vida personal relativa a la pertenencia de clubes, si han sido padres durante su estancia en prisión, su profesión, o quién era el cabecilla del grupo, todo ello aderezado con una música dramática. Al lado, una imagen con su cara pixelada y, para terminar, la imagen de los cinco sobre la que se puede leer la indemnización que deberán pagar y los delitos de los que han sido absueltos.

La noticia genera 535 comentarios, de los que 95 se manifiestan claramente en contra de la sentencia; 77, están a favor a favor al considerar la mayoría que la joven consintió y, el resto de comentarios o bien no tienen elementos para juzgar, o prefieren hablar de otros problemas sociales. En estos comentarios también se aprovecha para criticar el feminismo, al que se refieren como "mafia feminista" o "lobby feminista" que «destruye la relación de convivencia entre hombres y mujeres». 
- Sentencia "La Manada»: las feministas claman contra el fallo del juez: "No son abusos, es violación». (26/04/18, actualizada 15:34h.) Se trata del titular que encabeza otra de las noticias publicadas en los primeros minutos después de conocerse el fallo. Comienzan con el mismo encabezado "Sentencia La Manada»; se trata de una categoría para aunar todas las noticias sobre un mismo tema. De esta manera, el lector puede reconocer fácilmente y con un solo golpe de vista todas las informaciones que se publican en ese día sobre el caso. No hay vídeo y la imagen que ilustra esta noticia que no está escrita por ningún redactor del periódico, sino que está volcada de las informaciones recibidas por las agencias de noticias, corresponde a la fachada del Palacio de Justicia de Navarra rodeada por cámaras de TV, pero el titular sí es de elaboración propia. En él habla sobre el rechazo con el que fue acogida la sentencia y se refiere a esos manifestantes que se encuentran frente al Palacio de Justicia como "las feministas». Esta expresión puede resultar un tanto peyorativa o despectiva, ya que puede que haya más mujeres y hombres que también estén indignados y no se definan como feministas. Por eso se podría haber optado por otra expresión en el titular como: «colectivos feministas» o solo citar "colectivos». De esta manera reduce la crítica social a un colectivo concreto, trasladando la sensación de que la disconformidad con la sentencia es pequeña. En el cuerpo del texto, se reproducen los cánticos que se escuchaban tanto frente a la Audiencia Provincial como en redes sociales y que mostraban la disconformidad con el fallo. La noticia va acompañada de una fotografía, que pertenece a la Agencia EFE, en la que aparecen diferentes periodistas congregados frente al Palacio de Justicia a la espera de conocer la sentencia. En este caso, el sujeto de la noticia es "las feministas" y el tópico es la acción de clamar y posicionarse en contra de la sentencia dictada por el juez. El comento, lo que todavía el lector/a no conoce pero que focaliza la información es la oleada de indignación que comenzó a partir de los colectivos feministas mayoritariamente para situarse en contra de la sentencia. Esta noticia solo generó siete comentarios, pero curiosamente todos en contra de los movimientos feministas.

- ¿Quién es quién en «La Manada»? (26/04/18, actualizada 15:48h.) Bajo este titular el mismo periodista que redactó la primera noticia analizada, Pablo Ojer, realiza un retrato de los cinco acusados. Tal y como señala en el subtítulo, donde dice de ellos que "se conocen desde pequeños, de Amate, una de las zonas más pobres de España, aunque sus orígenes fueron corrientes y nada desestructurados». Apela al pasado de los acusados, a su infancia, para intentar remover la conciencia del lector. Utiliza unas frases con adjetivos cargados de significado: "pobres", "corrientes", "nada desestructurados». En el cuerpo del texto profundiza un poco en la vida y datos personales de cada uno de los cinco acusados: año de nacimiento, profesión y a modo de anécdota, cuanto algún detalle de su vida personal. Este texto está acompañado de un vídeo de elaboración propia donde, a partir de una fotografía de los cinco, aporta más datos personales (edad, profesión, otros delitos por los que se han ido condenados...). En este caso, el sujeto es otra vez «La Manada» y el tópico es la identificación de la culpabilidad que el redactor busca en los integrantes del grupo. Por otra parte, el comento se centra en la narración que realiza el redactor sobre el pasado y la infancia de los acusados: la relación de amistad, infancia pobre y difícil que vivieron, familias normales en las que se criaron... En esta noticia, vemos cómo a través de este comento oculto para el lector con el que apela al pasado de los encausados, el diario genera un proceso de humanización de estos, a través del cual se produce un intento 
de eliminación de la imagen de agresores. Esta noticia generó 27 comentarios, de los que diez se manifiestan claramente en contra de los condenados, tres consideran que no hay pruebas condenatorias claras y el resto de los comentarios son repetidos o hablan de generalidades.

- "La sentencia», columna de opinión de Carlos Herrera. (27/04/2018, actualizado 13:07h.) ABC.es publica un texto en su web el día 27 de abril escrito por el conocido periodista Carlos Herrera en el que opina y argumenta sobre los hechos acontecidos el día anterior. El subtítulo: «tenemos derecho a repugnarnos con que, en poco tiempo, estos tipos estén en la calle. Pero hay que leerse la sentencia", es la antesala y el resumen de la idea que el periodista va a desarrollar, defender y argumentar durante el cuerpo del texto. Condena los hechos y se refiere a los cinco integrantes de "La Manada» como «una serie de individuos borrachuzos y con la testosterona sobreactuada». Después se dirige al lector diciendo: «se me hace muy difícil asumirlo, igual que a usted", apelándolo y acercándose a él para inmediatamente después añadir una oración adversativa "pero la decisión del Tribunal está basada en relatos del Tribunal Supremo amén de la consideración que haya merecido el visionado de los vídeos. Yo no los he visto, aunque me los imagino, pero los jueces sím. Se muestra primeramente en contra de los hechos acontecidos y después, busca el punto de vista de los jueces para defender la decisión que tomaron. Comienza utilizando adjetivos con importante carga negativa contra los condenados: «brutales», "borrachuzos», "vergonzosamente machista", mostrando así su repulsa contra los hechos, pero después afirma que hay que leerse la sentencia para entender la decisión de los jueces y comienza a utilizar otro tipo de adjetivos: «insuficiente resistencia», "contrastada solvencia» $\mathrm{O}$ "aprovechamiento populista». Para Herrera, lo más importante es la sentencia (es el sujeto) y a través de ella, muestra su rechazo frente al abuso sexual que cometieron (tópico). Pero a su vez, el periodista quiere dejar claro algo al lector: es importante leer la sentencia y estar bien informado sobre el tema para sacar cada persona sus propias conclusiones, a la hora de opinar sobre el mismo (comento) por lo que deja la puerta abierta a manifestar la adhesión o no a la víctima. En cuanto a los 84 comentarios, generados, 33 se muestran claramente en contra de lo que sostiene Herrera y 28, claramente a favor. El resto opina de otras cosas.

De esta manera, el periodista utiliza como sujeto a la sentencia. El tópico es el abuso sexual y como foco informativo invita a leer la sentencia para que cada cual saque sus conclusiones, que pueden ser a favor o en contra. Utiliza como adjetivos «borrachuzos, brutales, insuficiente, contrastada, populista». 
TABla: 1. Este es el cuadro Resumen tratamiento ABC.eS

\begin{tabular}{|c|c|c|c|c|c|}
\hline $\begin{array}{l}\text { TITULAR Y } \\
\text { FECHA }\end{array}$ & SUJETO & TÓPICO & COMENTO & ADJETIVOS & $\begin{array}{c}\text { AUTO } \\
\text { RIA }\end{array}$ \\
\hline $\begin{array}{l}\text { Condenados los cinco } \\
\text { acusados a } 9 \text { años de } \\
\text { prisión por abuso } \\
\text { sexual. } \\
26 / 04 / 17\end{array}$ & $\begin{array}{c}\text { Los cinco } \\
\text { acusados } \\
\text { (La } \\
\text { Manada) }\end{array}$ & La condena & $\begin{array}{l}\text { Abuso sexual y } \\
\text { no violación }\end{array}$ & NO & Hombre \\
\hline $\begin{array}{l}\text { Las feministas claman } \\
\text { contra el fallo del } \\
\text { juez: "No son abusos, } \\
\text { es violacion". } \\
26 / 04 / 17\end{array}$ & $\begin{array}{l}\text { Las } \\
\text { feministas }\end{array}$ & $\begin{array}{l}\text { Protestas, } \\
\text { posicionarse } \\
\text { en contra }\end{array}$ & $\begin{array}{c}\text { Indignación por } \\
\text { la sentencia }\end{array}$ & NO & Agencias \\
\hline $\begin{array}{l}\text { ¿Quién es quién en } \\
\text { «La Manadaw? } \\
26 / 04 / 17\end{array}$ & $\operatorname{La}_{\text {Manada }}$ & $\begin{array}{c}\mathrm{La} \\
\text { descripción }\end{array}$ & $\begin{array}{c}\text { Amistad de los } \\
\text { chicos, contexto } \\
\text { familiar, } \\
\text { infancia: } \\
\text { humanización }\end{array}$ & $\begin{array}{c}\text { Pobres, } \\
\text { corrientes, nada } \\
\text { desestructurados }\end{array}$ & Hombre \\
\hline $\begin{array}{l}\text { La sentencia } \\
\text { (Opinion de Carlos } \\
\text { Herrera) } \\
27 / 04 / 17\end{array}$ & $\begin{array}{c}\mathrm{La} \\
\text { sentencia }\end{array}$ & $\begin{array}{l}\text { Rechazo al } \\
\text { abuso } \\
\text { sexual }\end{array}$ & $\begin{array}{l}\text { Invita a leer la } \\
\text { sentencia para } \\
\text { que cada cual } \\
\text { saque sus } \\
\text { conclusiones, } \\
\text { que pueden ser } \\
\text { a favor o en } \\
\text { contra }\end{array}$ & $\begin{array}{l}\text { Borrachuzos, } \\
\text { brutales, } \\
\text { insuficiente, } \\
\text { contrastada, } \\
\text { populista }\end{array}$ & Hombre \\
\hline
\end{tabular}

Fuente: ABC.es elaboración propia.

\subsection{Tratamiento informativo de Elpaís.com}

El tratamiento que este medio digital realiza de los hechos no es convencional. En vez de publicar varias noticias con la actualización de las diferentes informaciones que se van conociendo (como suele ser habitual), Elpaís.com apuesta por una noticia principal en la que recoge toda la información que va actualizando minuto a minuto con las novedades que se van conociendo. En este hilo informativo, no solo publica las novedades del caso, sino que aporta otro tipo de recursos como fotografías, tuits de diferentes políticos, testimonios de la calle... Además, es importante destacar que el periódico continúa con este hilo días después de la lectura de la sentencia, concretamente sigue con la actualización de noticias hasta el día 10 de mayo de 2018. Durante este tiempo, sigue cubriendo e informando de todas las reacciones a la sentencia acompañándolas de fotografías y vídeos. De esta forma, no solo realiza la cobertura mediática de los hechos el mismo día y el día posterior, sino que sigue informando de las reacciones actualizándolas a tiempo real. El titular que recoge todo el cuerpo del texto descrito anteriormente es: "Así te hemos contado las reacciones a la sentencia de «La Manada». Aparte de este hilo que se actualiza constantemente, el periódico también incluyó otras piezas en su web que informaban de los hechos de manera más detallada y pausada. Esta noticia generó dos comentarios, uno de apoyo a la víctima y otro criticando a la "Manada feminista». 
- «La Manada se libra de la violación». (26/04/18, actualizado 18:22h.) Este es el titular que encabeza una de las noticias que el diario digital Elpaís.com publicó el jueves 26 de abril, artículo escrito por Patricia Ortega Dolz. La expresión «librarse de» otorga a la frase un sentido condenatorio. Además, que la palabra «violación» aparezca en el titular deja entrever la brutalidad de los hechos, ya que prefiere utilizar «violación» en vez de "agresión sexual». La noticia está acompañada de un vídeo de la agencia Atlas que resume en un minuto la lectura de la sentencia. El cuerpo de texto es más extenso de lo habitual: 1.320 palabras en las que explica detalladamente la sentencia. Incluye párrafos de esta para justificar y argumentar sobre lo que está informando y añade un cuadro de texto en el margen izquierdo donde destaca algunas de las frases de la declaración de la víctima. Es importante destacarlo, ya que está dando vOz a la víctima en el desarrollo de la noticia, algo que en el análisis del anterior medio no ha aparecido. En este caso, como hemos visto, el sujeto vuelve a ser "La Manada" y el tópico es el verbo «librarse», con alta carga connotativa al condenar a los agresores y, también, poner en tela de juicio la decisión judicial. El comento (lo que el lector desconoce) será el abuso sexual y no la violación a la que han sido condenados los cinco acusados.

Esta noticia generó 2.597 comentarios de todo tipo desde la publicación el 26 de abril, hasta el cierre de los comentarios el 6 de mayo. La mayoría, de apoyo a la víctima y cuestionando la sentencia, aunque otra línea argumental se critica a la víctima por haberse metido en el portal.

"Juristas y expertas feministas critican la sentencia de La Manada: Es una vergüenza». (26/04/18, 20:08h.) Este titular lidera otra de las noticias que este medio publicó dos horas después de que se conociera la sentencia. Como ya apreciamos en el titular, la periodista Pilar Álvarez ha buscado uno de los puntos de vista que marcó la jorna$\mathrm{da}$, el de los colectivos feministas y cita una de las frases pronunciada por una de las integrantes: "Es una vergüenza». Eligiendo este titular está dando vOz a este colectivo que quiere denunciar públicamente la condena de los integrantes de "La Manada». El subtítulo sigue la misma tónica y afirma: "Si cinco personas que arrinconan a una chica no es agresivo, la pregunta es qué falla en el Código Penal», dice la exsecretaria de Estado de Igualdad, Soledad Murillo. Con este subtítulo plantea en el lector la cuestión que se puso encima de la mesa a raíz del dictamen: ¿qué falla en el Código Penal? En el cuerpo de la noticia la autora recoge testimonios y declaraciones de diferentes mujeres que ocupan cargos importantes en diferentes instituciones encargadas de la lucha contra la desigualdad de género. El vídeo que acompaña al texto es de la agencia Atlas y muestra una de las manifestaciones que se convocaron en noviembre mientras se celebraba el juicio. En este caso, el sujeto será «las juristas y expertas feministas» y el tópico la crítica ante la sentencia. El foco de atención se centra en quién lo expresa, en calidad de expertas. Con esta noticia, Elpaís.com se centra en visibilizar el descontento surgido ante la lectura de la sentencia por una parte de la sociedad y que está encabezado por asociaciones feministas.

Esta noticia generó 422 comentarios, desde el 26 al 30 de abril. Llama la atención el alto porcentaje de personas que se manifiestan en contra de la opinión de «juristas y expertas feministas", con un 19.64\%, frente al 8,92 \% que se posiciona a favor de este punto de vista. Un 8,03\% cuestiona que existan «expertas feministas», un 18,75\% habla de otros asuntos relacionados con la sentencia, pero no sobre esa noticia en particular y, también sorprende el elevado número de comentarios borrados por el medio de comunicación, un 44,64\%. 
- "¿Qué les digo a mis hijas?», columna de opinión de Luz Sánchez Mellado. (27/04/18, 07:59h.) En este caso, El país.com apostó por esta periodista para redactar una de las columnas de opinión que se publicaron horas después de conocerse la sentencia. En el titular plantea una pregunta y hace referencia a su propia experiencia personal para opinar sobre el dictamen. En forma de pregunta, Sánchez-Mellado se plantea la repercusión que esa sentencia va a tener en la libertad de las mujeres. Se muestra en contra de la sentencia y habla también de los comentarios en Twitter que culpabilizaban a la víctima cuando en dicha red social lanzó la pregunta "¿qué le digo a mis hijas?». Intenta reflexionar sobre cómo les contará esto a sus hijas y para ello, busca una explicación y la forma de aconsejarles (tópico). Lo que el lector descubre leyendo el texto es la incertidumbre e inseguridad que Sánchez-Mellado tiene respecto al futuro de todas las mujeres, encarnadas en sus hijas (comento), tras las consecuencias que generará, en su opinión, la sentencia y que es lo que posteriormente producirá muchas críticas por parte del público.

Esta noticia generó del 27 de abril al 1 de mayo, 550 comentarios. Un 37\% contestó a la pregunta de la periodista "¿Qué les digo a mis hijas?» grosso modo, que «si una mujer entra en un portal con cinco hombres ya sabe a qué va». El 46\% se enzarzó en un interesante debate en el que se habló, entre otros asuntos, sobre la culpabilización en una situación en la que "tiene que ser la mujer quien debe evitar el riesgo"; sobre el feminismo, sobre la prisión permanente; sobre quienes defienden a los de «La Manada"; sobre las condenas; sobre la "sociedad enferma" que permite la existencia de este tipo de delitos; sobre el alcohol y el sexo; la presión social y mediática a los jueces o las denuncias falsas, principalmente. Uniendo estos dos porcentajes, en la mayoría de los comentarios prevaleció la idea de que es la mujer quien debe evitar los riesgos, por lo que se culpabiliza, en cierta manera, a la víctima.

Un 14\% de los comentarios fueron borrados por el periódico y casi un 3\% contestó a la autora del artículo que la sentencia criminaliza tanto a los hombres como a las mujeres que además son víctimas. 
Tabla 2. Este es el CuAdro Resumen del tratamiento de Elpaís.com

\begin{tabular}{|c|c|c|c|c|c|}
\hline $\begin{array}{l}\text { TITULAR Y } \\
\text { FECHA }\end{array}$ & SUJETO & TÓPICO & COMENTO & ADJETIVOS & AUTORÍA \\
\hline $\begin{array}{l}\text { Así te hemos contado } \\
\text { las reacciones a la } \\
\text { sentencia de } \mathrm{L} \text { a } \\
\text { Manada } 26 / 04 / 18 \text { - } \\
10 / 05 / 18 \\
\text { (actualización } \\
\text { prolongada en el } \\
\text { tiempo) }\end{array}$ & $\begin{array}{c}\text { Sentencia } \\
\text { de } \mathrm{L}_{\mathbf{a}} \\
\text { Manada }\end{array}$ & $\begin{array}{l}\text { Informax en } \\
\text { directo }\end{array}$ & $\begin{array}{c}\text { La actualidad sobre } \\
\text { la sentencia }\end{array}$ & $\begin{array}{l}\text { (Información } \\
\text { aséptica, sin } \\
\text { adjetivación) }\end{array}$ & El País \\
\hline $\begin{array}{l}\text { La Manada se libra de } \\
\text { la violación } \\
26 / 04 / 17\end{array}$ & La Manada & $\begin{array}{c}\text { Asumir la pena } \\
\text { impuesta }\end{array}$ & $\begin{array}{l}\text { Carga emocional } \\
\text { con la que el } \\
\text { periódico genera la } \\
\text { sensación de que } \\
\text { La Manada es } \\
\text { culpable pero no } \\
\text { paga por ello }\end{array}$ & $\begin{array}{l}\text { No. Cita partes de } \\
\text { la sentencia con la } \\
\text { descripción de los } \\
\text { hechos }\end{array}$ & Mujer \\
\hline $\begin{array}{l}\text { "Juristas y expertas } \\
\text { feministas critican la } \\
\text { sentencia de } \mathrm{L}_{a} \\
\text { Manada: "Es una } \\
\text { vergüenza" } 26 / 04 / 17\end{array}$ & $\begin{array}{l}\text { Juristas y } \\
\text { expertas } \\
\text { feministas }\end{array}$ & $\begin{array}{c}\text { La crítica por } \\
\text { parte de } \\
\text { feministas }\end{array}$ & $\begin{array}{l}\text { Juristas mujeres y } \\
\text { feministas como } \\
\text { única autoridad }\end{array}$ & $\begin{array}{l}\text { Vergonzoso, } \\
\text { intolerable, } \\
\text { agresivo }\end{array}$ & Mujer \\
\hline $\begin{array}{l}\text { ¿Qué les digo a mis } \\
\text { hijas?" Opinión de Luz } \\
\text { Sánchez-Mellado } \\
27 / 04 / 17\end{array}$ & $\begin{array}{c}\mathrm{L}_{\mathrm{a}} \\
\text { periodista }\end{array}$ & $\begin{array}{l}\text { Aconsejar, } \\
\text { culpabilizax }\end{array}$ & $\begin{array}{c}\text { Consecuencias de } \\
\text { la sentencia }\end{array}$ & $\begin{array}{l}\text { Terrorífico, } \\
\text { delicadísima }\end{array}$ & Mujer \\
\hline
\end{tabular}

Fuente: Elpaís.com elaboración propia

\subsection{Tratamiento informativo de Eldiario.es}

$\mathrm{Al}$ igual que Elpaís.com, Eldiario.es apostó por una noticia principal en la que iba actualizando contenido conforme iban llegando datos nuevos. Esta forma de informar imita a la red social Twitter en la que se pueden crear hilos informativos que se van actualizando continuamente para ir añadiendo información. En este caso, Eldiario. es lo tituló de una forma sencilla y clara: "Directo. La sentencia del caso La Manada». Comenzó a actualizar esta pieza informativa el día 26 de abril y continuó añadiendo informaciones hasta el día 2 de mayo. De esta forma, recogió en un mismo espacio todas las respuestas que se generaron a raíz de la sentencia. Aunque al igual que Elpaís. com, esta no fue la única noticia que publicó para informar de los hechos, también encontramos otras piezas informativas que salieron ese mismo día y que analizaremos a continuación.

- «La justicia considera que no hubo violación y condena a La Manada a 9 años por abuso sexual». (26/04/18, 13:20h.). El artículo ha sido escrito por Ana Requena Aguilar y Marta Borraz. Este titular abre la noticia y en él los protagonistas no son ni «La Manada» ni la víctima, sino la justicia. Después, encontramos tres subtítulos asépticos y sin ninguna carga subjetiva que dan más detalles sobre la sentencia e, incluso, aclara brevemente la diferencia 
entre abuso sexual y agresión. "El Código Penal entiende que en el abuso sexual no media «violencia e intimidación», como sí lo hace en el delito de agresión sexual». El cuerpo del texto sigue la misma tónica que los subtítulos, no hay carga subjetiva ni frases hechas, se ciñen a aportar datos como los años de condena para cada uno, lo que en un principio pedía la Fiscalía, un breve resumen del juicio celebrado en noviembre de 2017. Todo esto va acompañado de un vídeo de elaboración propia en el que muestran la lectura completa de la sentencia por parte del magistrado. En este sobrio y objetivo tratamiento de la información, encontramos un sujeto novedoso que en los anteriores medios no habíamos identificado, "la justicia», que "considera» (tópico) que fue abuso sexual y no violación (comento, ya que el lector en ese momento todavía no conoce cuál es la condena ni la diferencia entre abuso y agresión). Utiliza una sinécdoque para comparar el todo por la parte, por lo que cuestiona a todo el poder legislativo.

Esta noticia generó 203 comentarios desde el día de su publicación, el 26 de abril, hasta el 28 de ese mismo mes. El $80 \%$ se muestran claramente en contra de la sentencia, frente al $8 \%$ que la justifican. Casi el $7 \%$ hacen comentarios sobre temas colaterales a la sentencia y al sistema judicial y el 5\% de los comentarios aparecen como borrados por el propio medio.

- "Cronología del caso La Manada: de la denuncia por violación a la condena por abusos sexuales". (25/04/18, 22:05h.). Se trata de una infografía que Eldiario.es publicó unas horas antes de la lectura de la sentencia, recogiendo toda la información sobre el caso desde el 7 de julio de 2016 cuando la víctima denunció los hechos hasta el mismo día en el que se produjo la lectura del fallo, el 26 de abril de 2018. En esta infografía aportan fotografías e incluso vídeos de los hechos destacados que muestran para así dar una visión general e integral a los lectores con el objetivo de situarlos de manera rápida y sencilla en el caso. Se trata de un completo trabajo periodístico que une, en un mismo espacio, todos los elementos que conforman los hechos. Partiendo de esta noticia anterior, Eldiario.es sigue en la misma línea y reúne en un artículo titulado "¿Qué diferencia hay entre abuso y agresión sexual? Preguntas y respuestas sobre la condena a "La Manada", varias preguntas con su correspondiente respuesta que muchos lectores podrían hacerse tras conocer la sentencia. Algunas de estas preguntas son: ¿Qué delito cometieron según el tribunal?, ¿qué significa prevalimiento?, ¿qué pedía la Fiscalía?, ¿qué es una agresión sexual? De esta manera, Eldiario. es sigue utilizando un tono divulgativo, no solo cuenta los hechos, sino que transforma la información para hacerla más comprensible y entendible por los lectores y lectoras. Esta segunda noticia continúa la misma línea que la anteriormente analizada; el sujeto en este caso es el caso "La Manada" y con ella, se pretende informar, contextualizar y realizar una cronología (tópico), para que el lector entienda la evolución de la denuncia por violación para terminar con una condena por abuso sexual (comento). No recoge comentarios por parte del público.

- "Condena ejemplar del patriarcado a las mujeres", columna de opinión de Violeta Assiego. (26/04/18, 16:14h.) Assiego es abogada y colaboradora habitual de este medio digital en el que suele escribir columnas de opinión sobre temas de igualdad de género. En este caso publicó un texto en el que se mostraba totalmente en contra de la sentencia dictada por el juez. De las tres columnas de opinión analizadas es la más directa y agresiva, algo que se ve en el subtítulo. En el desarrollo del cuerpo del texto utiliza la ironía y el sarcasmo para denunciar no solo la sentencia, sino la 
situación de coacción de libertad en la que se encuentras las mujeres ante los hombres. Critica duramente la decisión de los jueces calificando a la Justicia de «machista y patriarcal». Habla en primera persona del plural, apelando a las mujeres para mostrar así un conjunto, un nexo de unión, a las que insta a salir a la calle a manifestarse en contra de unos hechos que considera «injustos». En este caso, Assiego utiliza «la sentencia” como sujeto y protagonista de su artículo para mostrar la condena patriarcal (tópico) que, según ella, se ha producido a raíz de la lectura del fallo. Además, durante el cuerpo del texto quiere hacerle ver cómo las mujeres son infravaloradas y maltratadas por esa justicia a la que llama "patriarcal» y que genera consecuencias para las mujeres (comento). Esta columna generó 52 comentarios desde su publicación, el 26 de abril hasta el 17 de mayo, fecha del último comentario publicado. El 50\% se muestran a favor del análisis de la autora, mientras que el 17,3\% se muestran contrarios. El 15,3\% habla de temas relacionados y el resto son comentarios no mostrados por moderación del medio o de los socios.

Tabla 3. Este es el cuadro resumen del tratamiento de El Diario.es

\begin{tabular}{|c|c|c|c|c|c|}
\hline $\begin{array}{l}\text { TITULAR Y } \\
\text { FECHA }\end{array}$ & SUJETO & TÓPICO & COMENTO & ADJETIVOS & AUTORÍA \\
\hline $\begin{array}{c}\text { Directo. } \mathrm{La} \\
\text { sentencia del caso } \\
\text { La Manada } \\
26 / 04 / 18 \\
\end{array}$ & $\begin{array}{c}\text { Sentencia del caso } \\
\text { La Manada }\end{array}$ & $\begin{array}{l}\text { Informar en } \\
\text { tiempo real }\end{array}$ & $\begin{array}{c}\text { Ventana directa } \\
\text { del lector a la } \\
\text { noticia }\end{array}$ & $\begin{array}{c}\text { (Información aséptica, } \\
\text { sin adjetivación) }\end{array}$ & \\
\hline $\begin{array}{l}\text { "La justicia } \\
\text { considera que no } \\
\text { hubo violación y } \\
\text { condena a 'La } \\
\text { Manada' a } 9 \text { años } \\
\text { por abuso sexual'. } \\
26 / 04 / 17\end{array}$ & La justicia & Considerar & $\begin{array}{l}\text { Abuso sexual en } \\
\text { vez de violación }\end{array}$ & $\begin{array}{c}\text { (Información aséptica, } \\
\text { sin adjetivación). Se } \\
\text { limita a citar partes de } \\
\text { la sentencia }\end{array}$ & Dos mujeres \\
\hline $\begin{array}{l}\text { Cronología del caso } \\
\text { 'la manada': de la } \\
\text { denuncia por } \\
\text { violación a la } \\
\text { condena por abusos } \\
\text { sexuales. } 26 / 04 / 17\end{array}$ & Caso La Manada & $\begin{array}{c}\text { Cronología, } \\
\text { contextualizar }\end{array}$ & $\begin{array}{l}\text { Violación-abusos } \\
\text { sexuales }\end{array}$ & $\begin{array}{c}\text { (Información aséptica, } \\
\text { sin adjetivación) }\end{array}$ & El Diario.es \\
\hline $\begin{array}{l}\text { Condena ejemplar } \\
\text { del patriarcado a } \\
\text { las mujeres. } \\
\text { Opinión de } \\
\text { Violeta Assiego } \\
26 / 04 / 17\end{array}$ & Sentencia & Condena patriarcal & $\begin{array}{l}\text { Consecuencias de } \\
\text { la sentencia para } \\
\text { las mujeres }\end{array}$ & $\begin{array}{l}\text { Ejemplar, escandalosa, } \\
\text { machista, patriarcal. }\end{array}$ & Una mujer \\
\hline
\end{tabular}

Fuente: Eldiario.es elaboración propia.

\section{Conclusiones}

Tras analizar las noticias hemos detectado un tratamiento informativo dispar en los tres medios seleccionados: ABC.es, Elpaís.com y Eldiario.es. Respondiendo al primero de los objetivos planteados, (averiguar el grado de objetividad) se puede concluir que ABC.es, fundamentalmente y Elpaís.com no logran ser objetivos, mientras que Eldiario.es roza casi la plena objetividad.

En cuanto al segundo de los objetivos, averiguar el grado de homogeneidad en el tratamiento informativo en los tres medios, encontramos grandes diferencias en el tratamiento informativo, fundamentalmente en ABC.es respecto a los otros dos. 
ABC.es es el único de los tres medios analizados en el que se traslada cierta humanización de los integrantes de "La Manada" utilizando unas técnicas y recursos periodísticos concretos, como son la descripción de perfiles personales o la elaboración de un vídeo sencillo en el que se ofrecen cuatro datos de cada condenado con una música con tintes dramáticos e incluso épicos. Es el único medio en el que hemos detectado esto, ya que Elpaís.com se posiciona relativamente en contra y condena los hechos perpetrados por "La Manada». Mientras que Eldiario.es no realiza ningún juicio de valor en sus noticias y se mantiene neutral, limitándose a informar sobre los hechos.

Elpaís.com es el más crítico contra los integrantes de "La Manada» de los tres medios analizados en cuanto a tratamiento informativo. Utiliza expresiones más condenatorias y más adjetivos con carga connotativa en sus noticias. Aunque, sin embargo, su columna de opinión no es la más condenatoria ni radical de las tres.

El artículo de opinión de Eldiario.es, de Violeta Assiego es el más crítico de los tres en cuanto a la sentencia leída por los jueces. Utiliza un duro tono, con adjetivos con alta carga negativa, a través de los cuales pretende hacer ver al lector/a que «la sentencia es una consecuencia del sistema patriarcal en el que vivimos actualmente».

De los tres medios analizados, el mejor tratamiento periodístico, el más completo, con más elaboración propia, recursos gráficos, infografías, vídeos es el de Eldiario.es, ya que no solo informa de los hechos, sino que publica artículos con mayor profundización, contextualización y detalle. Además, en las noticias en las que informa de las novedades sobre el caso y sobre la lectura de la sentencia, no utiliza adjetivos que den una carga subjetiva al contenido; se limita a dar una información objetiva y aséptica.

Por todo lo expuesto, consideramos que el análisis realizado a la información sobre la sentencia de "La Manada" vertida en tres cibermedios arroja una conclusión determinante como es que estos tres medios han generado tres formas distintas de informar sobre la sentencia. En ABC.es la imparcialidad y objetividad no se han vislumbrado con la fuerza necesaria para lograr una equidistancia profesional de toda la polémica levantada por la sentencia. La información «humanizada» sobre los autores, el circunscribir la crítica a la sentencia a "las feministas" y el comentario de Herrera abierto a múltiples interpretaciones, entre las que se encuentra la de leer en profundidad el voto particular parece inclinar la balanza hacia quienes creen que lo que hicieron los condenados fue consentido por la víctima.

El País.es, sin embargo, denota con sus informaciones y artículo de opinión una tendencia alineada con quienes creen que la sentencia no creyó a la víctima, mientras que Eldiario.es ofrece equidistancia entre los dos polos y logra informar de manera neutral.

En cuanto al tercer objetivo, detectar la presencia de la ideología de género en las informaciones, es evidente que se ha dado de manera expresa en la información periodística de $\mathrm{ABC}$.es. En este diario es evidente la plasmación de ideología de género en su información en la que de manera intencionada o no, se desprestigia el movimiento feminista. En ElPaís.com, se vislumbra ciertos destellos de ideología de género en favor de la mujer, víctima de los hechos, así como del movimiento feminista y en Eldiario.es este tipo de ideología sólo aparece en el artículo de opinión.

Por último, se ha determinado que el tratamiento informativo ofrecido por los tres medios sí ha motivado la movilización de las personas, al menos en las redes y a través de los comentarios. Estos ofrecen una instantánea, una respuesta ciudadana 
a la sentencia casi en tiempo real a la publicación de las informaciones, no solo para mostrar la indignación, sino también para todo lo contrario.

Puede decirse que los comentarios del público, en estos y en otros medios, así como las manifestaciones en numerosas ciudades españolas y algunas en otros países, no solo sirvieron como altavoz para mostrar las opiniones de una parte de la ciudadanía, sino que también pueden ser tomados como una de las causas de que el Gobierno de España empezara a poner sobre la mesa la posible reforma del Código Penal para estos casos.

Estas informaciones también han dejado ver la formación de una conciencia social de mujeres como colectivo que quiere terminar con una larga y perniciosa tradición patriarcal que no cree a la mujer. Consideramos que esta reacción social a la sentencia puede suponer un resquebrajamiento de los pilares del patriarcado.

En los comentarios también se visibiliza una conciencia social más de hombres que apoyan la causa de estas mujeres y que también la han hecho suya. También se vislumbra una movilización de mujeres y hombres en busca del cambio social que conforme otro tipo de sociedad más igualitaria y justa.

Las personas movilizadas en contra de la sentencia han hecho una radiografía de lo que supone el patriarcado: no creer a la víctima.

\section{REFERENCIAS}

Atencio, G. (Ed.). Agresiones sexuales múltiples en España. Informe. 2016-2018. Obtenido de: https://geoviolenciasexual.com

Bell, A. (1991). The language of news media. Oxford, Blackwell.

Bardin, L. (1996). Análisis de contenido. Madrid, España, Akal.

Calero, J. M. y Ronda, J. (2000). Manual de periodismo judicial. Sevilla, Universidad de Sevilla

Campoamor, Clara ([2010]). El voto femenino y yo. Mi pecado mortal. Madrid, España, Ed. Diario Público.

Cobo Sáenz, J. F. Sentencia no 38/2018 de fecha 20 de marzo de 2018, dictada en el sumario n ${ }^{\circ}$ 426/2016. Obtenido de: https://bit.ly/2QdeNqt

De Miguel, Ana (1995). Los Feminismos, en Amorós, Celia (Dtra), Diez palabras clave sobre la mujer, Pamplona, España, Editorial Verbo Divino.

Kaplan, Temma (1990). "Conciencia femenina y acción colectiva: el caso de Barcelona, 19101918”, en Amelang, James S. y Nash, Mary (eds.) Historia y Género: las mujeres en la Europa moderna y contemporánea. Valencia, España, Alfons el Magnánim.

Miyares, Alicia (1999). Revista Leviatan, $\mathrm{n}^{\circ} 75$, Madrid. Recuperado de: https://bit.ly/2Fk8Gxn

Núñez Ladevéze, L. (2015). Periodismo en la red: géneros, estilos y normas. Madrid, España, Universitas Editorial.

Paino Ambrosio, A., Jiménez Iglesias, L. y Rodríguez Fidalgo, Mª. I. (2016). La imagen de la mujer en las crónicas de Carmen de Burgos Colombine durante la Guerra de Marruecos. Historia y Comunicación Social. Vol 21, número 2, pp. 413-432

Puleo, Alicia H. (1993). La Ilustración olvidada: La polémica de los sexos en el siglo XVIH / Condorcet, De Gouges, De Lambert y otros; presentación de Celia Amorós. Barcelona: Anthropos

Ramos, María Dolores (1993). «Madres de la Revolución? Mujeres en los movimientos sociales españoles, 1900-1930", en Georges Duby y Michelle Perrot, (Dtrs). Historia de las mujeres en Occidente. El siglo XX, Vol. 5. (bajo la dirección de Françoise Thébaud), Madrid: Taurus.

Sanfeliú, L. (2005). Republicanas. Identidades de género en el blasquismo [1895-1910], Universidad de Valencia, en Establier Pérez, Helena (2011) La dama roja: literatura y pacifismo en 
Carmen de Burgos Seguí (Colombine) Analecta Malacitana, Universidad de Málaga, XXXIV, pp. 435-454. 2011. ISSN 0211-934X. Recuperado de: https://bit.ly/2TzusBe

Sebastian y Latre, Thomas (1987). Relación individual, y verídica del suceso acontecido en la ciudad de Zaragoza el día 6 de abril de 1766. Estudio preliminar Fernando Baras Escolá y Francisco Javier Montero Hernández, Zaragoza: Librería General.

Van Dijk, Teun A. (1980). Texto y contexto. Barcelona, Cátedra.

Van Dijk, Teun A. (1990). La noticia como discurso. Comprensión, estructura y producción de la información. Barcelona, Paidós.

Van Dijk, T. (1999). El análisis crítico del discurso. Barcelona, Anthropos.

Wodak R. y Meyer. M. (2003). Métodos de análisis crítico del discurso. Barcelona, Gedisa,

Zarzalejos Nieto, José A. (1998). Encuentro entre Jueces y Periodistas, organizado por el Consejo General del Poder Judicial, y la Asociación de la Prensa de Madrid, Madrid:

\section{WeBgrafía}

Agencias (26/04/18). Sentencia "La Manada» las feministas claman contra el fallo del juez: "No son abusos, es violación». ABC.es. Obtenido de: https://bit.ly/2wWcOyV

Agencia Efe (18/10/2017). El juicio por la violación grupal en Sanfermines de 2016 será a puerta cerrada. En el Diario.es. Obtenido de: https://bit.ly/2NZsuHX

Agencia Efe (7/7/2016). Prisión por delitos de agresión sexual para los cinco detenidos en Pamplona. Públcio.es. Obtenido de: https://bit.ly/2wWatnj

Agencia Europa Press (26/04/2018). Concentraciones en toda España en protesta por la sentencia a "La Manada». Obtenido de: https://bit.ly/2KZB1dp

Álvarez, P. (26/04/18). Juristas y expertas feministas critican la sentencia de «La Manada»: «Es una vergüenza». Elpaís.com. Obtenido de: https://bit.ly/2FkOJmq

Assiego, V. (26/04/18). Condena ejemplar del patriarcado a las mujeres. Eldiario.es. Obtenido de: https://bit.ly/2HSAmeB

Benede, I. (26/04/2018). La vista oral del juicio contra "La Manada" levantó gran polémica. Eitb. eus. Obtenido de: https://bit.ly/2QgFWsI

ElConfidencial.com (29/04/18). Las manifestaciones por el polémico fallo judicial de "La Manada» llegan a París. Elconfidencial.com. Obtenido de: https://bit.ly/2kkHbs0

Eldiario.es (25/04/18). Cronología del caso "La Manada»: de la denuncia por violación a la condena por abusos sexuales. Eldiario.es. Obtenido de: https://bit.ly/2Cxd3Wn

Eldiario.es (26/04/18). Directo. La sentencia del caso "La Manada». Eldiario.es. Obtenido de: https://bit.ly/2oRBROY

Elía, N. (16/11/2017). Las conclusiones de las defensas de 'La Manada" y las de las acusaciones serán públicas. En el Diario.es. Obtenido de: https://bit.ly/2wUsmCb

Elía, N. (11/11/2017). Los acusados de la violación grupal de San Fermín se enfrentan a 22 años de cárcel. Obtenido de: https://bit.ly/2NqW4sS

ElPaís.com (13/07/2018). Los agresores de una joven en Pamplona grabaron la violación. Elpaís. Obtenido de: https://bit.ly/2QgnEaY

ElPaís.com (10/05/18). Así te hemos contado las reacciones a la sentencia de "La Manada». Elpaís.com. Obtenido de: https://bit.ly/2MdfT22

ElPaís.com (5/12/2018). El Tribunal Superior de Navarra confirma la condena de "La Manada» a nueve años de cárcel por abuso sexual. Obtenido de: https://bit.ly/2SsHL60

Europa Press (2018, 27 de abril). Zoido, abierto a revisar la legislación tras la sentencia contra "La Manada» para acomodarla al sentir de la sociedad. El Diario.es Obtenido de: https://bit. ly/2wSCEn 4

Herrera, C. (27/04/18). La sentencia. ABC.es. Obtenido de: https://bit.ly/2wUcznJ

La Vanguardia, 16 de septiembre de 1907. Obtenido de: https://bit.ly/2L0QVEk

Ojer, P. (26/04/18). Sentencia de «La Manada»: Condenados los cinco acusados a 9 años de cárcel por abuso sexual. ABC.es. Obtenido de: https://bit.ly/2rOEOyc 
Ojer, P. (26/04/18). ¿Quién es quién en «La Manada»? ABC.es. Obtenido de: https://bit.ly/2NqLvGq Ortega Dolz, P. (26/04/18). "La Manada» se libra de la violación. Elpaís.com. Obtenido de: https://bit.ly/2HVs2eg

Requena, A. (26/04/18). La justicia considera que no hubo violación y condena a "La Manada» a 9 años por abuso sexual. Eldiario.es. Obtenido de: https://bit.ly/2r1F67g

Sánchez-Mellado, L. (27/04/18). ¿Qué les digo a mis hijas? Elpaís.com. Obtenido de: https://bit. ly/2HONkdg

Sánchez E. (28/04/18). \#Cuéntalo: las mujeres comparten sus historias de abusos y agresiones sexuales. ElPaís.com. Obtenido de: https://bit.ly/2CxkJba 